\title{
(Des)fazendo percursos do modernismo: revisão de conceitos
}

\author{
Ivete Lara Camargos Walty* \\ Paulo Roberto Tonani do Patrocínio**
}

O centenário da Semana de Arte Moderna, evento consagrado pela crítica canônica como marco fundador do modernismo brasileiro, faz-se momento oportuno para a produção de um revisionismo crítico do movimento e de conceitos que o sustentaram. Nacionalismo, colonialismo, antropofagia, identidade, em diálogo com seus contrários como cosmopolitismo, antropoemia e alteridade, formam uma espécie de seara conceitual que revela o diálogo entre o discurso contemporâneo e as produções modernistas. Mais do que uma inspiração ou uma possível apropriação de modulações críticas, a presença de alguns conceitos-chave do modernismo na contemporaneidade deve ser compreendida como uma espécie de resíduo das questões propulsoras do pensamento modernista brasileiro. Além disso, é igualmente possível ratificarmos que a busca de identidade nacional figura no centro de tais reflexões, sempre marcada por relações de poder de várias naturezas.

Considerando o persistente debate ${ }^{1}$ crítico sobre a questão da identidade brasileira, caracterizado por um movimento pendular entre os polos de modelo e cópia, continuidade e ruptura, provincianismo e cosmopolitismo, interessa-nos observar como se delineiam mapas espacio-temporais ontem e hoje. Ao analisar

\footnotetext{
* Pesquisadora CNPQ.

** Universidade Federal do Rio de Janeiro (UFRJ).

1 Ver, como ilustração, os textos: O entre-lugar da literatura latino-americana - Santiago, 1971; Apesar de dependente, universal - Santiago - 1980; As ideias fora do lugar - Schwarz, 1973; Nacional por subtração - Schwarz, 1986; Nacionalismo e subdesenvolvimento. Candido, 1973; Nacionalismo: uma palavra instável. Candido, 1995; Nacional por abstração - Eneida Maria de Souza, 1998; Literatura anfíbia - Santiago, 2002.
} 
esse movimento pendular que marca a produção cultural brasileira, Paulo Arantes, retomando Antonio Candido e Roberto Schwarz, assinala dois movimentos que teriam tentado defender a autonomia cultural brasileira, o movimento Pau-Brasil oswaldiano e o tropicalismo. Assim refere-se o autor a esses movimentos:

Posso apenas referir de passagem um outro caso de avaliação estética da dualidade, igualmente estudado por Roberto Schwarz. Trata-se da composição do poema pau-brasil, do qual no fundo é variante, como se sabe, a montagem tropicalista. 'A sua matéria-prima se obtém mediante duas operações: a justaposição de elementos próprios ao Brasil-Colônia e ao Brasil burguês, e a elevação do produto - desconjuntado por definição à dignidade de alegoria do país"” (ARANTES, 1989, p.40).

Defendendo a importância da dialética nos estudos de então, o autor é taxativo em relação aos movimentos que usam a alegria com fator de afirmação, deixando de lado as questões econômicas, políticas e sociais:

Oswald de Andrade dará uma resposta positiva aos dilemas da dualidade. O que o complexo colonial interiorizara como atraso e desgraça, o desrecalque pau-brasil converterá em motivo de euforia, já que a vanguarda emparelhava nosso primitivismo com a cultura dos países centrais." (ARANTES, 1989, p.40).

O movimento dialético proposto por Paulo Arantes nos permite realizar um outro exame crítico que se baseia no estudo da permanência de conceitos e questões que atravessam a história do modernismo brasileiro à luz dos estudos similares aos do sociólogo Boaventura de Souza Santos (2009), fazendo movimentar linhas abissais. Isso significa reler movimentos 
modernistas, como a Semana de Arte Moderna, os manifestos, as revistas, levando em consideração experiências culturais contemporâneas, como a arte periférica, feminina, negra, entre outras.

Em sua proposta de desenhar mapas alternativos de construção de saberes, Boaventura Souza Santos (2009), discorre sobre "alternativas à epistemologia dominante", ressaltando a importância da diversidade como representação de "um enorme enriquecimento das capacidades humanas para conferir inteligibilidade e intencionalidade às experiências sociais". O autor português afirma: "Designamos a diversidade epistemológica do mundo como epistemologias do Sul." E continua:

O Sul é aqui concebido metaforicamente como um campo de desafios epistêmicos que procuram reparar os danos e impactos historicamente causados pelo capitalismo na sua relação colonial com o mundo. (SANTOS, 2009, p.12).

Trata-se de transposições daquilo que o sociólogo (2010) chama de linhas abissais: linhas, literais e metafóricas, que separam a construção do conhecimento, conferindo visibilidade e validade a apenas um dos lados. $\mathrm{O}$ autor mostra como tais linhas, marcadas, por exemplo, no processo de colonização, mantêm-se, tomando novas formas no mundo moderno e no contemporâneo. Afirma, então, na proposição do que seria um pensamento pósabissal: "A injustiça social global está, desta forma, intimamente ligada à injustiça cognitiva global” (SANTOS, 2010, p. 31-32)

Interessa-nos acrescentar mais um termo a essa equação, a produção de populações periféricas em sua tentativa de visibilidade e audibilidade, sobretudo com os movimentos 
ligados à poesia Pau-Brasil e à antropofagia, como a "Semana de Arte Moderna da Periferia" e o "Manifesto da antropofagia periférica", de Sérgio Vaz, ambos de 2007. Comecemos com as fotos e os cartazes representativos dos movimentos.

FIGURA 1 - Foto oficial da Semana de Arte Moderna de $1922^{2}$

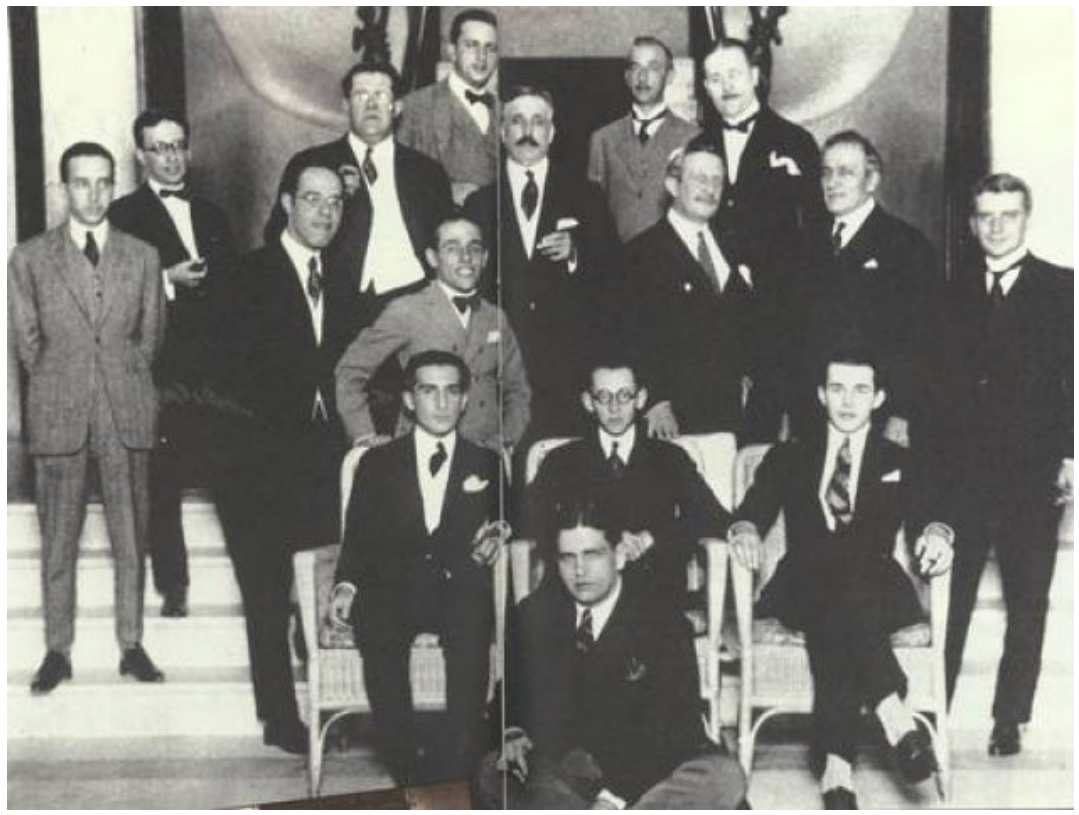

Fonte: AMARAL, Aracy A. Artes plásticas na Semana de 22, 1970. 
FIGURA 2 - Capa do programa da Semana de Arte Moderna de 22

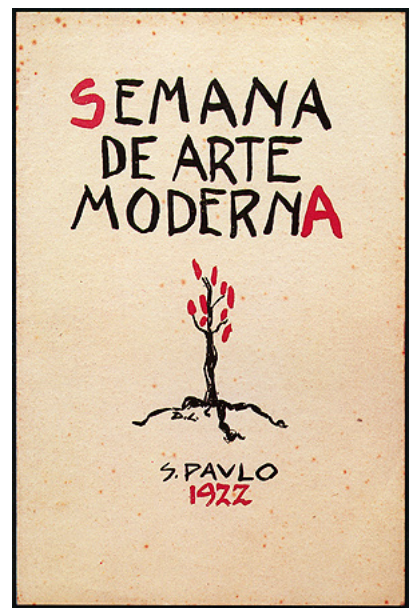

Fonte: FIALDINI, Itaú Cultural, 2022.

FIGURA 3 - Foto oficial da Semana de Arte Moderna da Periferia - A Semana de 2007

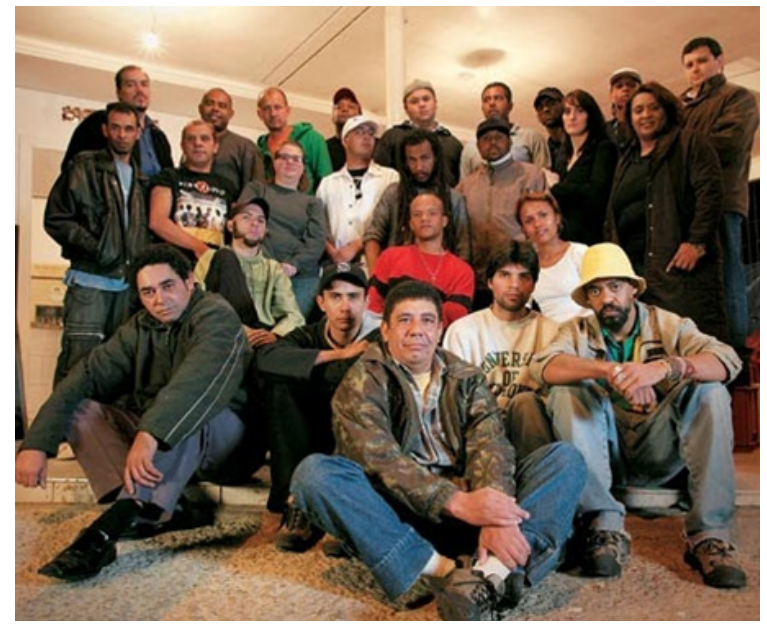

Fonte: Revista Época, Edição n0487, em 18 set. 2007. 
FIGURA 4 - Cartaz da Semana de Arte Moderna da Periferia 2007, autoria de Jair Guilherme.

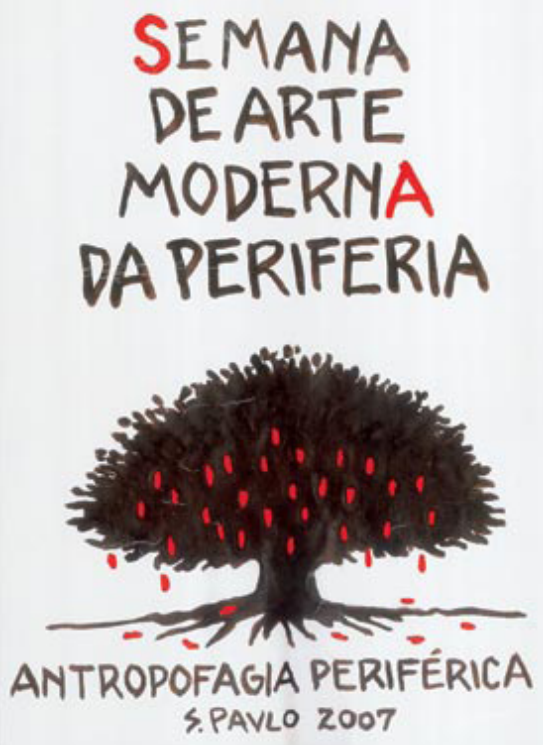

Fonte: Revista Época, Edição 487, em 14 set. 2007.

O diálogo estabelecido entre os dois movimentos manifestase em vários níveis de apropriação antropofágica: na cópia do título e do desenho do cartaz, na foto dos organizadores e, depois, como se verá, na retomada dos manifestos. A cada elemento tomado, uma reafirmação e um deslocamento, uma cópia e uma ruptura. A roupa usada pelos participantes bem como a cor de sua pele aponta para o Brasil das duas diferentes épocas em suas contradições. A árvore, símbolo tão usado para se referir à relação entre a cultura colonizadora e a colonizada, ganha robustez e volume na copa, nas raízes à mostra e, principalmente, na quantidade de frutos.

A Semana de Arte Moderna da Periferia, com a explícita alusão à Semana de 22, foi realizada em novembro de 2007 pelo grupo de poetas da periferia, com destaque para a atuação de 
Sergio Vaz. A noção norteadora da Semana é a criação de um espaço para a veiculação das produções culturais de artistas da periferia dentro e fora da própria periferia. Como já afirmado, em semelhança à Semana de 22, o material de divulgação do evento também se baseia na apresentação de uma árvore. Mas, a apropriação que o grupo realiza do símbolo insere uma significativa diferença; no lugar da árvore seca e com poucos galhos, como a criada por Di Cavalcanti, os artistas periféricos apresentam um baobá frondoso e repleto de frutos. A utilização do vermelho para demarcar os frutos favorece uma associação ao sangue, símbolo máximo da violência urbana que assombra as periferias. De uma forma ou de outra, a imagem do cartaz dialoga diretamente com o sentido que o evento buscava imprimir nas manifestações culturais de então, compreendendo estes espaços marginalizados como polos de uma rica produção cultural que recebe pouca visibilidade.

Pastiche e apropriação, esses são os conceitos que podem ser utilizados para interpretar o evento, pois, conforme explica Sérgio Vaz, o grupo reunido na idealização e realização da Semana tinha como principal norte a postura política e artística assumida pelos intelectuais paulistas de 1922: "comer a arte enlatada produzida pelo mercado que nos enfiam goela abaixo, e vomitar uma nova versão dela, só que desta vez na versão da periferia. Sem exotismos, mas carregada de engajamento." (Vaz, 2008 , p. 235). O sentido antropofágico ainda se faz presente e surge como ato norteador da postura dos artistas, mas o diálogo que se almeja estabelecer é outro. Para os poetas da Cooperifa não é a relação entre a cultura nacional e a cosmopolita que emerge como elemento de debate do fazer artístico. Ao contrário, o foco se torna local e possui um endereço específico: os bairros marginalizados, as ladeiras das favelas e os conjuntos habitacionais. A antropofagia irá orientar o contato do artista 
periférico, oriundo destes espaços, com a arte produzida nos centros da economia, da academia, da cultura e da política.

Junto da proposta de evento e da utilização da antropofagia como conceito norteador das ações, Sérgio Vaz também produziu o Manifesto da Antropofagia Periférica. Em semelhança aos documentos elaborados por grupos de vanguarda, o texto assinado pelo coordenador da Cooperifa também é baseado no tom assertivo direcionado em dois movimentos: a favor e contra.

A antropofagia oswaldiana é agora reeditada, mas repetida em diferença. Na versão periférica do Manifesto não cabe interrogar: "Tupi or not tupi-This is the question". Isso porque não é ponto de debate aventurar-se no questionamento sobre a linguagem e a acomodação de ideias e propostas estéticas em solo nacional. Sérgio Vaz, no entanto, realiza uma espécie de homenagem a este trecho do Manifesto assinado por Oswald ao escrever: "Miami pra eles? "Me ame pra nós!". O jogo que o autor estabelece é semelhante ao movimento criado por Oswald; ambos utilizam princípios de uma tradução cultural para reforçarem os aspectos que defendem em seus manifestos.

Elementos imagéticos da poesia Pau-Brasil são potencializados nesse Manifesto periférico, como, por exemplo, tanto "O Carnaval. O Sertão e a Favela. Pau-Brasil. Bárbaro e nosso", como o "País de dores anônimas". (ANDRADE, 1974). O poema "falação", poema síntese do Manifesto Poesia PauBrasil (18/03/1924), descreve assim o país que, no momento posterior, encena a passagem do ruído à palavra periférica, concretizando um ato político, como o define Rancière (2018), marcado pelo dissenso.

$\mathrm{Na}$ mesma direção Sérgio Vaz aponta sua crítica ao consumo de uma cultura e de uma arte pasteurizada e enlatada, sem engajamento. No texto "Caminhos de um poeta cidadão", publicado como prefácio do livro Literatura, pão e poesia, de 
Sérgio Vaz, diz a crítica Heloisa Buarque de Hollanda,

Sugiro com ênfase um estudo comparativo dos dois manifestos e instintos antropofágicos ali registrados. $\mathrm{O}$ pesquisador, além de encontrar muito assunto para se debruçar, vai se deliciar espelhando e especulando sobre esses dois momentos sintomáticos do século XX e do século XXI, respectivamente. (HOLLANDA, 2011, p. 12).

O olhar da crítica é pontual e coloca em evidência a singularidade dos momentos em que os respectivos manifestos foram produzidos. O instinto antropofágico de Sérgio Vaz, que surge na periferia e se alimenta do centro, passa a ser compreendido como um reflexo direto das condições contemporâneas.

$\mathrm{O}$ manifesto assinado pelo poeta da periferia ecoa um tom de violência, de confronto, mas não deixa de lado a música e a dança:

A favor de um subúrbio que clama por arte e cultura, e universidade para a diversidade. Agogôs e tamborins acompanhados de violinos, só depois da aula. Contra a arte patrocinada pelos que corrompem a liberdade de opção. Contra a arte fabricada para destruir o senso crítico, a emoção e a sensibilidade que nasce da múltipla escolha.

A Arte que liberta não pode vir da mão que escraviza.

A favor do batuque da cozinha que nasce na cozinha e sinhá não quer. Da poesia periférica que brota na porta do bar. (VAZ, 2007).

Novos espaços se constroem abrindo espaço para saraus, editoras e slams que hoje povoam as ruas das cidades brasileiras.

Da Literatura das ruas despertando nas calçadas. A Periferia unida, no centro de todas as coisas. Contra o racismo, a intolerância e as injustiças sociais das quais a arte vigente não fala.

É preciso sugar da arte um novo tipo de artista: o artistacidadão. Aquele que na sua arte não revoluciona o mundo, 
mas também não compactua com a mediocridade que imbeciliza um povo desprovido de oportunidades. Um artista a serviço da comunidade, do país. Que, armado da verdade, por si só exercita a revolução.

Contra a arte domingueira que defeca em nossa sala e nos hipnotiza no colo da poltrona.

Contra a barbárie que é a falta de bibliotecas, cinemas, museus, teatros e espaços para o acesso à produção cultural. (VAZ, 2007).

O colonizador agora está dentro de casa, mas continua lançando seus cordéis visíveis ou invisíveis:

Contra os vampiros das verbas públicas e arte privada. A Arte que liberta não pode vir da mão que escraviza. Por uma Periferia que nos une pelo amor, pela dor e pela cor.

É TUDO NOSSO! (VAZ, 2007).

No Manifesto é possível identificar o desejo de compreensão da cultura periférica por parte destes autores da margem. Predomina nesse aspecto uma percepção sonhadora, talvez utópica, da força revolucionária da cultura, quando observam a si próprios como produtores de uma arte autônoma, não contaminada pelas estruturas hegemônicas. Além disso, a escrita, o fazer literário, assume uma feição política de intervenção direta na realidade social e cultural. "A Arte que liberta não pode vir da mão que escraviza." a sentença, presente duas vezes no Manifesto, reafirma o claro intento de elaborar uma arte engajada e, principalmente, fora dos espaços do predomínio das forças políticas que atiraram esses poetas à margem.

Vale recorrer mais uma vez a Heloísa Buarque de Hollanda, quando, no texto citado, chama atenção para o papel desse segmento social na série histórica da literatura brasileira:

O poeta vira-lata, como se autodenomina Sérgio Vaz, 
percebeu com maestria o poder político da aquisição e instrumentalização segura da palavra e torna essa descoberta um ativismo de inclusão social diário e obstinado. (HOLLANDA, 2011, p. 12).

O gesto realizado por Sérgio Vaz pode ser identificado também no projeto do rapper Emicida ao 'ocupar' o Theatro Municipal de São Paulo com o lançamento do álbum "AmarElo". Segundo a leitura de Roberta Maria Ferreira Alves, no artigo "Ver-te em "Amarelo", que abre o nosso dossiê, o mesmo palco, que recebeu o evento consagrado pela historiografia hoje canônica enquanto ato inaugurador do modernismo, sofre uma ocupação ressignificada ao receber o show do artista negro da periferia de São Paulo. Em noite histórica única, estabeleceramse diálogos incomuns entre a Arte erudita e a Arte popular; entre o espaço da elite e a população da periferia. Na leitura de Roberta Alves, nesse mesmo espaço, viu-se uma São Paulo, normalmente excludente, encenada por pessoas representantes da diversidade, produzindo e consumindo uma arte nacional híbrida. Hibridez apontada também pela apropriação dos versos da música "Sujeito de sorte", de Belchior, na canção que intitula todo o processo (1976):

Tenho sangrado demais, tenho chorado pra cachorro Ano passado eu morri, mas esse ano eu não morro Tenho sangrado demais, tenho chorado pra cachorro Ano passado eu morri, mas esse ano eu não morro Ano passado eu morri, mas esse ano eu não morro Ano passado eu morri, mas esse ano eu não morro.

(BELCHIOR, 1976)

Nesse trânsito que vimos apontando, propomos um exercício crítico que se baseia no ato de revisitar alguns conceitos forjados no modernismo, pensando o ano de 1922 enquanto data catalisadora das diferentes questões que mobilizam esse debate. Os artigos aqui reunidos realizam um percurso muito peculiar 
acerca desta reflexão, propondo uma revisão de momentos, que, corroborando ou rompendo com alguns desses conceitos, são propícios para a discussão de traços da identidade nacional brasileira. Nesse sentido, examinando ecos da Semana de 22, Vinícius André Minhoto da Costa propõe uma releitura do Tropicalismo por meio do que chama suas canções-síntese, "Alegria, Alegria" e "Baby", em um movimento inverso ao proposto por Roberto Schwarz, revisitado por Paulo Arantes, já que defende o caráter incorporador, do Tropicalismo, que agregaria "os contrastes existentes no país como naturalmente partes da própria cultura nacional, [e também] somando-os às inovações do mundo pop, engrossando desse modo a geleia geral."

$\mathrm{O}$ artigo "Do mito do senhor benevolente à mulatização: o negro no pensamento estético-político de Oswald de Andrade", assinado por Mário Fernandes Rodrigues e Roberto Alexandre do Carmo Said, estabelece uma mirada crítica sobre a questão negra ao problematizar o complexo pensamento desenvolvido por Oswald de Andrade. Os autores indicam que, ao construir uma visão triunfalista do passado colonial e escravocrata brasileiro, após a Semana de Arte Moderna de 1922, Oswald de Andrade antecipou argumentos que seriam utilizados pelos defensores da democracia racial, falácia que viria a ser contestada pelas novas gerações de intelectuais descomprometidos com as estruturas tradicionais da nação. Bruno Lima, no artigo "A construção de um Brasil imaginado estética e ideologicamente", aciona o pensamento de Benedict Anderson para realizar um percurso crítico semelhante, que se baseia no questionamento do caráter inautêntico e postiço de algumas imagens cristalizadas de nossa identidade nacional.

Elegendo como objeto de estudo uma das revistas da época, Rafael Guimarães e Telma Borges da Silva trabalham justamente 
com a metáfora do movimento especular que, ao mesmo tempo, reflete e refrata traços de pessoas e eventos, quando, em "Entre luzes e refrações: Mário Klaxista de Andrade", analisam a relação do modernista de primeira hora com a revista Klaxon e com a sociedade brasileira de então.

Também trabalhando com um dos periódicos, no artigo "Indigestão colonial em alguns poemas da Revista de Antropofagia", Rodrigo Octávio Cardoso discute o avesso da antropofagia, a antropoemia, conceito ligado ao ato de expelir, implícito na palavra indigestão. A problemática relação da produção cultural brasileira no papel de buscar seu lugar "no concerto das nações"33 continua a desdobrar-se, pois, em várias direções, como já antevisto na produção crítica da segunda metade do século XX.

Não por acaso, nessa abertura de encruzilhadas, Luís Felipe Abreu usa, já em seu título, a expressão cunhada por Silviano Santiago para lidar com a dicotomia entre colonizador e colonizado, cosmopolitismo e provincianismo. Em "O entrelugar da ex-apropriação: despossessão e propriedade nas escrituras falsas de Gloria Alzáldua e Édouard Glissant”, o autor atravessa as fronteiras do Brasil, fazendo dialogar o conceito com outros ligados ao universal processo de apropriação. Seu percurso, como era seu propósito, permite ao leitor "ler textos poéticos transculturais" por tal chave - levando a uma compreensão da apropriação e da imitação como movimentos de um roubo que escancara a precária performance da posse"

Como se vê, o mapa se alarga tanto geográfica como culturalmente, em movimentos de interseção, como o que pode ser percebido no artigo "Modernismo/Hipermodernismo: o debate teórico italiano contemporâneo, de Leonardo Ferreira Aguiar. Estendendo também o tempo sobre o qual se debruça, o

3 Expressão usada por Silviano Santiago.

4 Os textos entre aspas são trechos dos artigos em pauta no corpo da apresentação. 
autor discute os conceitos Moderno/Pós-Moderno, Modernismo/ Pós-Modernismo e Hipermoderno, sem perder de vista os movimentos do presente conturbado que vivemos, como afirma: "hoje, 100 anos depois dos modernismos europeus e à porta do centenário da Semana de Arte Moderna no Brasil, o mundo parece replicar tensões análogas às do início do século passado, sendo que as guerras no Oriente Médio, a pandemia do Novo Coronavírus, a guinada generalizada ao conservadorismo e ao totalitarismo e afins são vetores que expõem uma ferida a qual se acreditava ter cicatrizado há pelo menos 30 anos, com o fim da polarização da Guerra Fria."

Como se vê, a vitalidade do conceito de antropofagia pode ser mensurada não apenas devido ao seu lugar totêmico na cultura brasileira, mas, principalmente, por assumir a função de um operador de leitura, conforme mostra Maria José Araújo, no artigo "Os sinos da agonia: um banquete barroquizante a ser degustado aqui e agora", que visita a antropofagia enquanto lugar teórico, estético e político. Esse procedimento possibilita mostrar como Autran Dourado, em Os sinos da agonia, recorre ao barroco como estilo de escrita, estilo que apela para a experiência humana, imbricada no jogo metafórico, num verdadeiro desdobramento de imagens, em movimento que dá forma ao caótico mundo humano. Com recurso crítico semelhante, Luciana Brandão Leal, no artigo "Virgílio de Lemos e sua antropofagia delirante: estética e vertigem na lírica moçambicana", encena movimentos de devoração da cena das vanguardas europeias, enviesadas por um olhar estrábico, para usar a expressão de Ricardo Piglia (2012) em sua leitura do lugar do escritor latino-americano. Essa referência nos mostra, inclusive, como conceitos criados para dar conta de uma conjunção de eventos deslocam-se para outros lugares como também se deslocam movimentos de produção e recepção culturais. 
Sobre a série poética brasileira, versam os artigos sobre Carlos Drummond de Andrade "máquina do mundo" e a filosofia do absurdo: Drummond, leitor de Albert Camus", de Cleber Ranieri Ribas de Almeida, e "Carlos Drummond de Andrade: da cultura impressa às mídias digitais, de Janeide Sousa Santos. O primeiro, observando o processo de composição intertextual do famoso poema de Drummond, chama atenção especialmente para o "diálogo poético com o livro Le Mythe de Sisyphe (1942), de Albert Camus. Já o outro volta o olhar para o presente e, atento ao momento da recepção e da circulação, analisa o uso dos poemas do autor itabirano nas redes da Internet. Também na busca de inserção da autora no quadro de propostas do que se convencionou chamar Modernismo, no artigo "Cecília Meireles, uma lírica no auge do modernismo", Ana Amélia Neubern Batista dos Reis propõe alargar tal quadro aí incluindo o diálogo da autora com a tradição hindu.

Também Andréa Portolomeos, em "A crônica de Benjamim Costallat: uma nova ideia de literatura para a ampliação do público leitor através de jornais cariocas, nos anos de 1920", busca alargar as molduras do quadro modernista, mostrando "como o cronista trabalha à revelia de um conceito tradicional da cultura e do literário, dando origem a uma importante ruptura estética no Brasil que implicou - para além de uma exclusiva renovação da linguagem artística - a utilização de novos suportes, como o jornal e de novas tecnologias, como o cinema."

Em "Dois artistas de Minas Gerais na Semana de Arte Moderna: revisão e descentramento do Modernismo de 22", Ivana Ferrante propõe discorrer sobre aqueles que, presentes nos eventos da Semana, teriam caído no esquecimento: o poeta Agenor Barbosa e a pintora Zina Aita. Essa lente de exclusão e inclusão é lançada também na leitura de um "Retrato da poesia contemporânea quando em deslocamento com o modernismo", 
de Luis Henrique Garcia Ferreira e Luana Signorelli Faria da Costa.

Uma intrigante entrevista de Fernando Breda com o professor Carlos Berriel, da Unicamp, versa sobre o modernismo, como "um movimento artístico de relação bastante significativa com as oligarquias cafeeiras paulistas. Algo um tanto distante das visões mais consagradoras do movimento, que muitas vezes qualificam-no como um momento da cultura brasileira de ruptura estético-social com um certo marasmo político-cultural predominante no país até então".

Observam-se, pois, caminhos imbricados entre as reflexões empreendidas no interior dos artigos e entre os artigos, o que evidencia a dificuldade de visualizar linhas abissais percebendo os jogos de poderes aí encenados. Por isso, exercitando mais um ato antropofágico, citamos Sérgio Vaz, no texto "Receita para ser feliz", de Luiz Ruffato (2021): "para alcançar utopias é preciso enfrentar a realidade".

\section{Referências}

ANDRADE, Oswald de. O manifesto antropófago. In: TELES, Gilberto Mendonça. Vanguarda européia e modernismo brasileiro: apresentação e crítica dos principais manifestos vanguardistas. Petrópolis: Vozes; Brasília: INL, 1976.

ANDRADE, Oswald de. Por ocasião da descoberta do Brasil. In: Poesias completas. Rio de Janeiro: Civilização brasileira, 1971, p.77.

AMARAL, Aracy. Artes plásticas na Semana de 22, 1970.

BELCHIOR, Antonio Carlos. Sujeito de sorte. In: Alucinação. 1976. Disponível em https://www.letras.mus.br/belchior/344922/ Acesso em 13 de novembro de 2021.

ARANTES, Paulo Eduardo. Sentimento da dialética na 
experiência intelectual brasileira: dialética e dualidade segundo Antonio Candido e Roberto Schwarz. Rio de Janeiro: Paz e Terra, 1982.

CANDIDO, Antonio. Nacionalismo e subdesenvolvimento. In: América latina em sua literatura. São Paulo: Perspectiva, 1979, p.343-362.

CANDIDO, Antonio. Nacionalismo: uma palavra instável. In: Folha de S. Paulo, 1995. Disponível em http://www1.folha.uol. com.br/fsp/1995/8/27/mais!/27.html. Acesso em 13 de outubro de 2021

FIALDINI, Romualdo. Reprodução fotográfica da capa do programa da Semana de Arte Moderna de 22. Itaú Cultural. Disponível em: https://enciclopedia.itaucultural.org.br/ obra35328/capa-do-programa-da-semana-de-arte-moderna-de22-autoria-de-di-cavalcanti.

Foto oficial da Semana de Arte Moderna da Periferia. Revista Época, Edição no487, set. 2007. Disponível em: http:// revistaepoca.globo.com/Revista/Epoca/0,,EDG79089-6014,00OS+NOVOS+ANTROPOFAGOS.html.

GUILHERME, Jair. Cartaz da Semana de Arte Moderna da Periferia 2007.Revista Época, Edição 487, em 14 set. 2007. Disponível em: http://revistaepoca.globo.com/Revista/ Epoca/0,EDG79070-5856,00.html.

HOLLANDA, Heloísa Buarque de. Caminhos de um poeta cidadão. In: VAZ, Sérgio. Literatura, pão e poesia. História de um povo lindo e inteligente. Rio de Janeiro: Global, 2011.

PIGLIA, Ricardo. Uma proposta para o novo milênio. Tradução de Marcos Visnadi. Disponível em https://pt.scribd.com/ doc/217564040/RICARDO-PIGLIA-Proposta-para-o-novomilenio.

RANCIÈRE, Jacques. Políticas da escrita. Tradução de Raquel Ramalhete et al. São Paulo: Editora 34, 2017.

RANCIÈRE, Jacques. O desentendimento: política e filosofia. Tradução de Ângela Leite Lopes. São Paulo: Editora 34, 2018. 
RANCIÈRE, Jacques. A partilha do sensível. Tradução de Mônica Costa Neto. São Paulo: Editora 34, 2009.

RAFFATO, Luiz. Receita para ser feliz. In: Ninguém em casa. Curitiba: Maralto, 2021, p. 94-95.

SANTIAGO, Silviano. O entre-lugar da literatura latinoamericana. In: Uma literatura nos trópicos. Recife: CEPE, 2019, p. 9-30.

SANTIAGO, Silviano. Apesar de dependente universal. In: Vale quanto pesa. Ensaios sobre questões político-culturais. Rio de Janeiro: Paz e Terra,1980, p.13-24.

SANTIAGO, Silviano. Literatura anfíbia. In: O cosmopolitismo do pobre. Crítica literária e crítica cultural. Belo Horizonte: Editora da UFMG, 2004, p.64-73.

SANTOS, Boaventura Souza; MENESES, Maria Paula. Epistemologias do sul. Coimbra: Almedina, 2009.

SCHWARZ, Roberto. A carroça, o bonde e o poeta modernista. In: Que horas são? São Paulo: Companhia das Letras, 1987, p. 11-28

SCHWARZ, Roberto. Nacional por subtração. In: Que horas são? São Paulo: Companhia das Letras, 1987, p. 29-48

SCHWARZ, Roberto. As ideias fora do lugar. In: Ao vencedor as batatas, São Paulo: Duas Cidades, 1992.

SOUZA, Eneida Maria. Nacional por abstração. Revista Semear, 3, 1998. Disponível em http://www.letras.puc-rio.br/ unidades\&nucleos/catedra/seminari/sem_06.html. Acesso em 13 out. 2021.

VAZ, Sérgio. Manifesto da antropofagia periférica, outubro de 2007. Disponível em. https://diplo.org.br/imprima1967. Acesso em 13 out. 2021. 